\title{
Removal of a Peripheral Odontogenic Fibroma: A Practical Case from the Ordination for Dental Surgery and Implantology
}

\author{
Andreas Willer* \\ Zahnarzt, Oralchirurgie, Implantologie, Germany
}

*Corresponding author: Andreas Willer, Zahnarzt, Oralchirurgie, Implantologie, Germany, E-mail: info@zahnchirurgie-willer.de

Received: 12 Dec, 2019 | Accepted: 31 Dec, 2019 | Published: 10 Jan, 2020

Citation: Willer A (2020) Removal of a Peripheral Odontogenic Fibroma: A Practical Case from the Ordination for Dental Surgery and Implantology. Int J Dent Oral Health 6(1): dx.doi.org/10.16966/2378-7090.313

Copyright: (c) 2020 Willer A. This is an open-access article distributed under the terms of the Creative Commons Attribution License, which permits unrestricted use, distribution, and reproduction in any medium, provided the original author and source are credited.

\section{Summary}

In the present case, a treatment option for the removal of odontogenic peripheral fibroma is presented. In an operative procedure the electrosurgical excision of an extensive finding as well as the modeling of the gingiva in the lower jaw regio $43-45$ was carried out. This procedure ensured safe and complete removal of the fibroma and acceptable aesthetic reconstruction. A peripheral odontogenic fibroma is an absolute rarity and will be discussed in this article in the context of a case presentation.

Keywords: Peripheral odontogenic fibroma; Odontogenic tumor; Benign tumor

\section{Anamnesis and Preoperative Course}

A 37 -year-old patient presented after referral from the family dentist with a request for assessment and treatment of persistent mucosal change in the lower jaw for over a year. The patient reported a significant increase in size within the last 3 months and had already noticed a protrusion of the extra oral soft tissues of the cheek right side (Figure 1). He had experienced a subjectively increasing foreign body sensation as well as problems with food intake and oral hygiene.

The intraoral dental status showed a conservative sufficient restaurated full dentition at the first presentation of the patient in our practice. In addition to discoloration caused by coffee, tea and red wine consumption and tartar in the area of the mandibular front, there were no other abnormalities of the hard tooth substances.

Clinically impressed a painless, $2 \mathrm{~cm} \times 2 \mathrm{~cm} \times 1 \mathrm{~cm}$ large, polyposeplump-elastic regional finding. This tumor in the right lower jaw was mounted in regio 42-46 and pedunculated to regio 43/44. Careful folding of the tumor showed teeth 43-45 intact (Figure 2).

To supplement the diagnostic an orthopantomogram was created.

In the upper and lower jaw, metal-rich shadows in the area of the molars of the left and right upper and lower jaw as well as in the right anterior region of the right upper jaw showed up in the sense of preserving fillings. The radiograph revealed no periapical or intraosseous lesions. In particular, the regio 42-46 was inconspicuous.

The two sinus maxillares were free and well ventilated. The region of the temporomandibular joints presented on both the right and left side without pathological changes (Figure 3).

In summary of the clinical and radiographic findings, the working diagnosis of Epulis fibrogranulomatosa was made.

\section{Operational course}

After pain relief by local anesthesia with UDS forte (adrenaline $1: 100,000$ ), the tumor was electrosurgically excised (Figure 4) followed by the electrosurgical modellation of marginal gingiva in regio 43/44 (Figure 5). A gum bandage was not necessary.

\section{Postoperative course and prognosis}

The postoperative course was without complications. The patient was instructed first to use a soft toothbrush to care for the regio 43/44 to protect the marginal gingiva. It was also recommended to use a mouthwash solution (Chlorhexamed/0.2\%) over a period of 10-14 days $2-3 \times / d$ for local wound healing support.

At a follow-up 10 days postoperatively, an almost completely healed site was found in regio 43/44 (Figures 6 and 7). 6 months later a full regenerated site in regio 42 to 46 was found! The patient was completely symptom-free at this time, had no problems with food and fluid intake, and was able to regain full day-to-day oral hygiene. The patient will be closely supervised for the next 2 years in a recall for follow-up in the practice.

\section{Histological Findings}

The histological findings showed a bulging, slightly thickened layer of keratinizing squamous epithelium. Intra-and subepithelial, loose mixed-cell inflammatory infiltrates were found. Furthermore, a myxoid loosening, pseudocystic areas and changing lymphangiectasias could be detected. In a further treatment of the material, mucous swelling could be demonstrated as part of the Alcian Blue reaction. In addition, epithelial esters (Malassez's epithelium esters) were found.

\section{Discussion and Conclusion}

In 2017, the revised WHO classification of odontogenic tumors was 


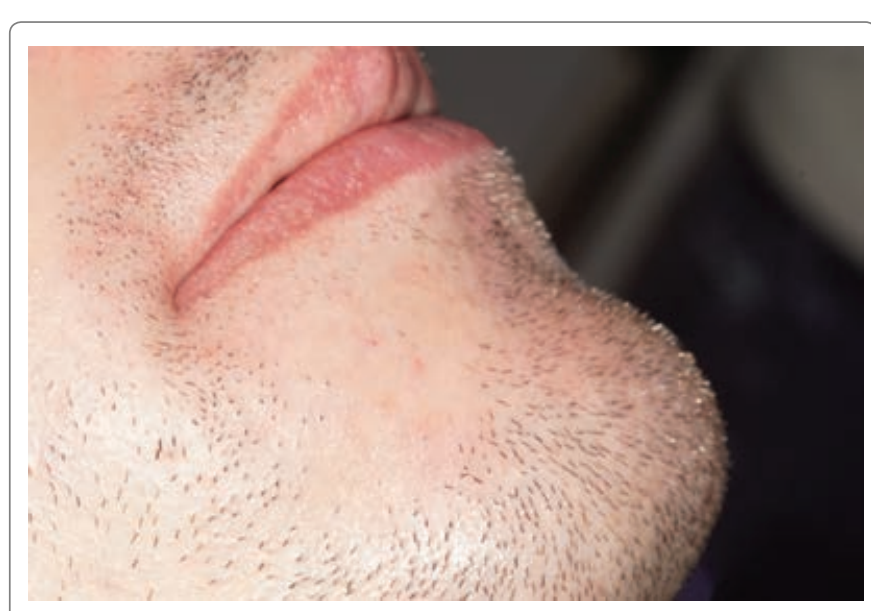

Figure 1: Presentation of the extra oral situs with protrusion of the cheek below the right corner of the mouth.

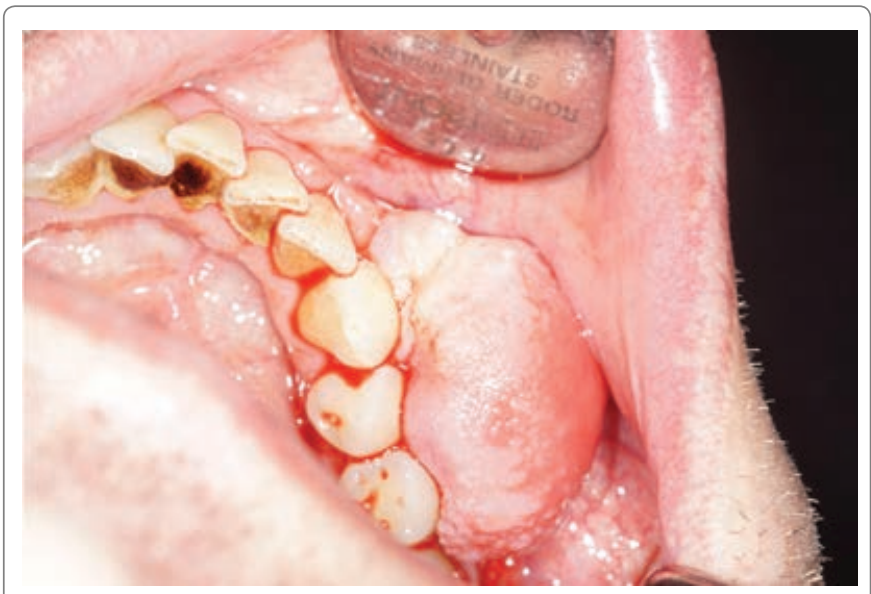

Figure 2: Illustration of the intraoral site (bleeding provoked by infiltration anesthesia).

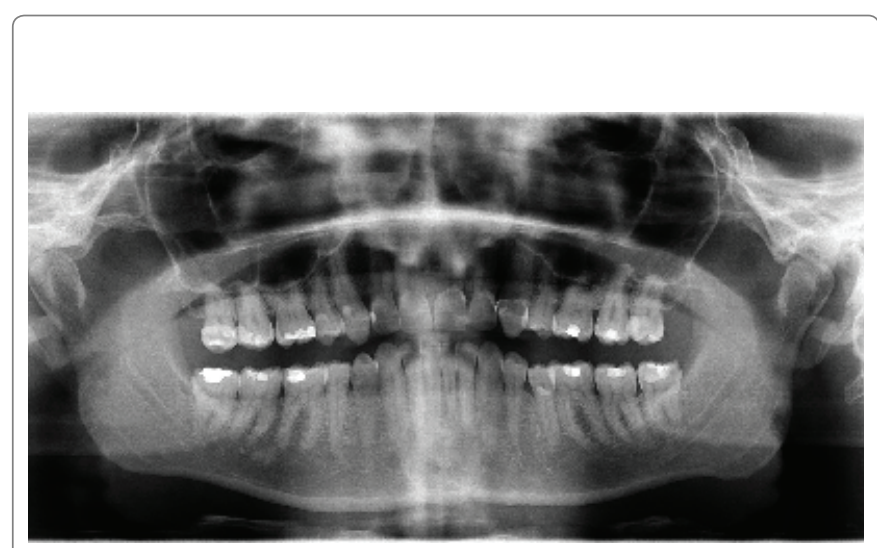

Figure 3: Pre-op. made OPG.

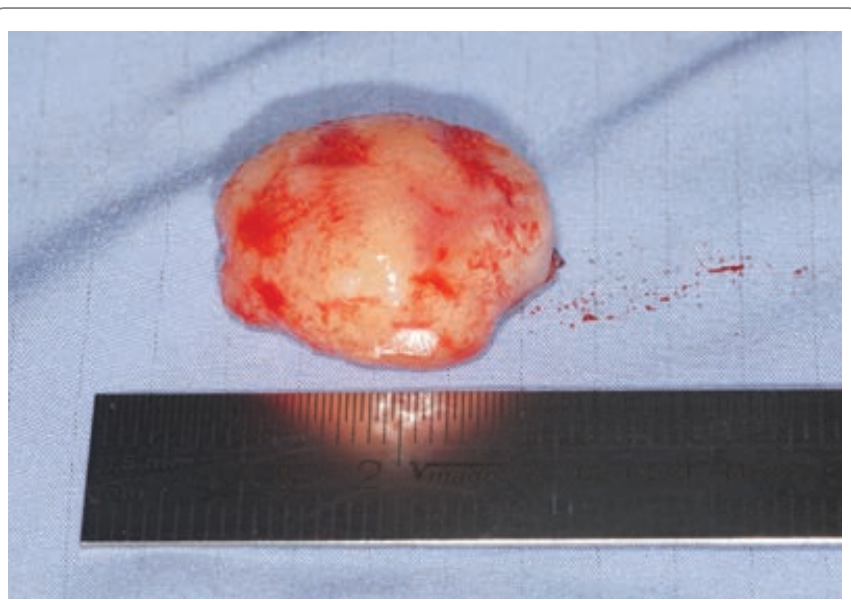

Figure 4: Excised tumor region 43-44.

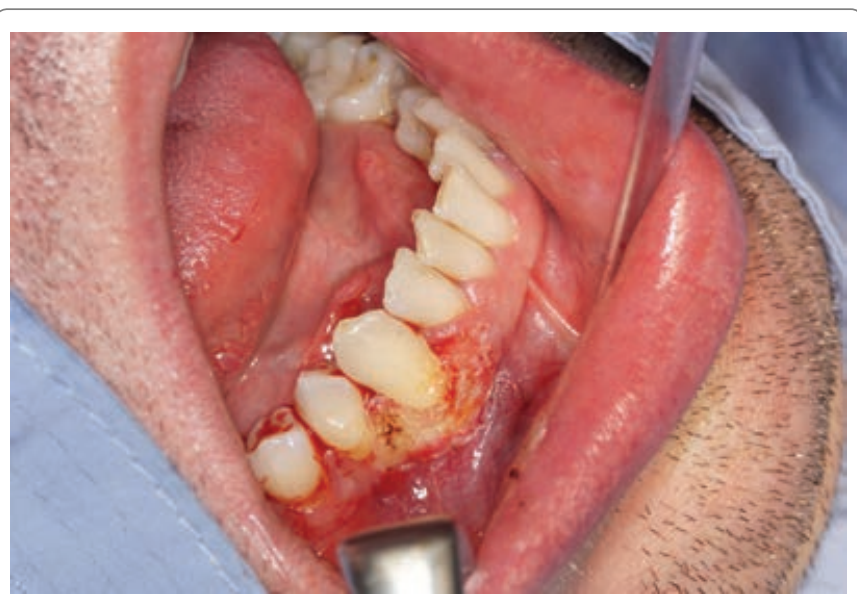

Figure 5: Situs regio 43/44 after electrosurgical excision and after modeling of the marginal gingiva.

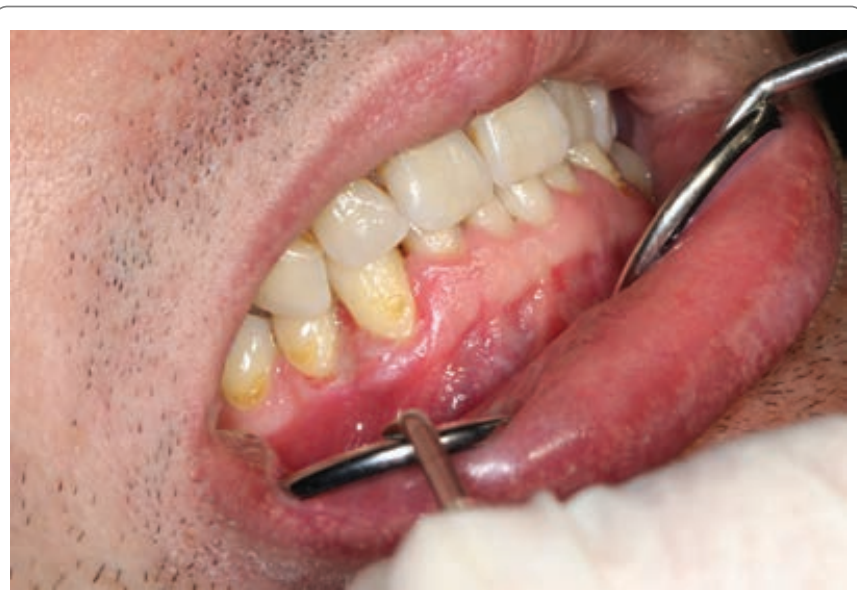

Figure 6: Situs regio $43 / 44$ after initial healing 10 days postoperatively. 
Table 1: Histologically, two different types of odontogenic fibroma can be distinguished according to the current WHO classification [3].

\begin{tabular}{|c|c|c|}
\hline Type/Specifications & Simple Type & Complex Type \\
\hline Epithelium & Low & Numerous \\
\hline Cells & Low/Fine collagen mesh & Dense cellular tissue composite \\
\hline Basic Substance & Fibromyxoid (Barnes L, et al. [3]) & $\begin{array}{l}\text { Fibroblastac cumulations, small blood vessels, islands } \\
\text { of scattered odontogenic epithelial cells }\end{array}$ \\
\hline Special Features & $\begin{array}{l}\text { - Inactive odontogenic epithelium (rare) } \\
\text { - Calcifications (rare) } \\
\text { - Dysplastic dentinum, Cement or bone formations } \\
\text { (Barnes L, et al. [3], Allen CM, et al. [6] Neville B, et al. [5]) }\end{array}$ & $\begin{array}{l}\text { Numerous odontogenic epithelium cells (Barnes L, et } \\
\text { al. [3] Neville B, et al. [5]) }\end{array}$ \\
\hline
\end{tabular}

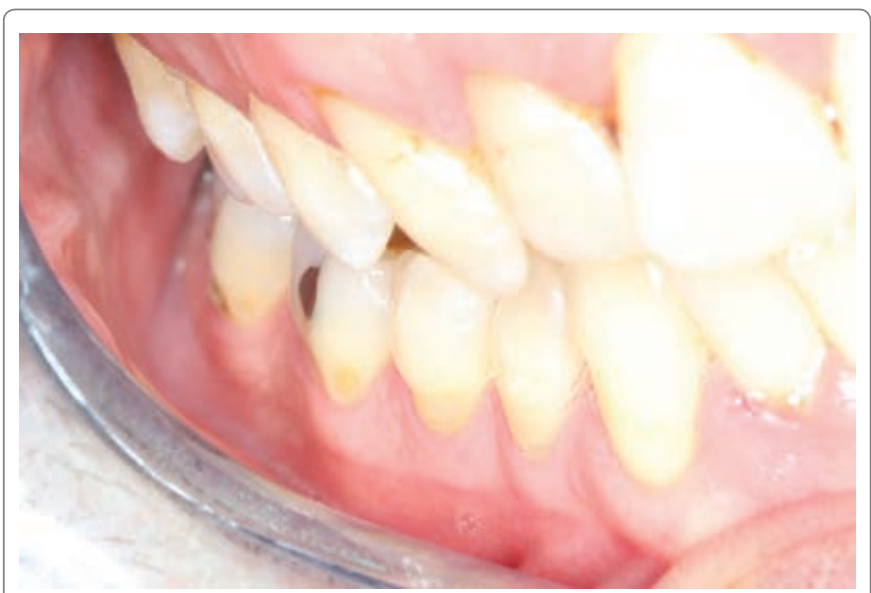

Figure 7: Situs regio 42/46 after complete healing and remodeling 6 months postoperatively.

presented. In this review, odontogenic fibroma is described as benign mesenchymal neoplasia originating in odontogenic mesenchymal connective tissue [1-3].

The odontogenic fibroma is divided into central intraosseous and peripheral extraosseous tumors, according to their primary location. The first-mentioned variant is much more frequently observed and occurs preferentially in the female sex, whereas significantly less frequent peripheral odontogenic fibroma occurs more frequently in the male population [3-5].

Considering the odontogenic fibroma in relation to all other odontogenic tumors, they are rather rare with a share of $5 \%$. They can occur in all age groups, but there is a special percentile in the frequency distribution for the period between the 30 th and $50^{\text {th }}$ year of life $[3,5]$.

Localization of the central, intraosseous tumor may be both upper and lower jaw. In the area of the maxilla, the anterior region is more frequently affected; in cases of occurrence in the area of the mandible, an accumulation of occurrence in the area of the premolar can be observed down to the molar area $[6,1]$.

Radio diagnostic findings on odontogenic fibroids can be quite variable. In most cases, well-defined, rounded radiolucencies, which are mostly in contact with tooth roots, are shown. This proximity can lead to resorption of roots, but also to displacements and tilts of teeth. Larger fibroids may be multilocular and show a partially sclerotic rim [7].
Macroscopically, it presents itself as white/solid and shows only a very small tendency to infiltrate (Table 1).

If one summarizes the microscopic features of the odontogenic fibroma, the odontogenic fibroma consists mainly of connective tissue stroma. Odontogenic epithelial cell nests or strands may occur as in the case presented, but are not obligatory [1].

Other forms of expression may be the odontogenic fibroma of the giant-granulomatous type [6] and that of the granule type [8].

The therapy of the odontogenic fibroma aims a complete surgical removal of the tumor, which shows usually a good limitation of the lesion. Recurrences are rarely observed. A malignant degeneration tendency is not described [9].

\section{References}

1. Pindborg JJ, Kramer IRH, Torloni H (1971) Histological typing of odontogenic tumours, jaw cysts, and allied lesions. World Health Organization, Geneva 36.

2. Gundlach KKH (2000) Thema Mund-, Kiefer-und Gesichtschirurgie 4: S187.

3. World Health Organization, International Agency for Research on Cancer (2005) In: Barnes L, Eveson JW, Sidransky D, Reichart P (eds) Pathology and Genetics of Head and Neck Tumours. IARC Press, Lyon, France.

4. de Villiers Slabbert H, Altini M (1991) Peripheral odontogeniv fibroma: A clinicopathologic study. Oral Surg Oral Med Oral Pathol 72: 86-90.

5. Neville B, Damm DD, Allen C, Bouquot J (2008) Oral and Maxillofacial pathology. $3^{\text {rd }}$ Edition, Philadelphia, USA.

6. Allen CM, Hammond HL, Stimson PG (1992) Central odontogenic fibroma, WHO* type: A report of three cases with an unusual associated giant cell reaction. Oral Surg Oral Med Oral Pathol 73: 62-66.

7. Jundt G, Reichart PA (2008) Benigne odontogene ektomesenchymale Tumoren. Pathologe 29: 199-204.

8. Shiro BC, Jacoway JR, Mirmiran SA, McGuirt Jr WF, Siegal GP (1989) Central odontogenic fibroma, granular cell variant $A$ case report with S-100 immunohistochemistry and a review of the literature. Oral Surg Oral Med Oral Pathol 67: 725-730.

9. Handlers JP, Abrams AM, Melrose RJ, Danforth R (1991) Central odontogenic fibroma: Clinicopathologic features of 19 cases and review of the literature. J Oral Maxillofac Surg 49: 46-54. 